\title{
DO ACCURATE STOCK ESTIMATES INCREASE HARVEST AND REDUCE VARIABILITY IN FISHERIES YIELDS?
}

\author{
JOHANNA MYRSETH \\ Arups gate 10A, 0192 Oslo, Norway \\ KATJA ENBERG \\ Institute of Marine Research, P.O. Box 1870, N-5817 Bergen, Norway \\ MIKKO HEINO \\ Department of Biology, University of Bergen, \\ P.O. Box 7803, N-5020 Bergen, Norway \\ Institute of Marine Research, Bergen, Norway \\ International Institute for Applied Systems Analysis, Laxenburg, Austria \\ $\varnothing$ YVIND FIKSEN* \\ Department of Biology, University of Bergen, \\ P.O. Box 7803, N-5020 Bergen, Norway and Uni Research, 5020 Bergen, Norway
}

\begin{abstract}
Fisheries managers normally make decisions based on stock abundance estimates subject to process, observation, and model uncertainties. Considerable effort is invested in gathering information about stock size to decrease these uncertainties. However, few studies have evaluated benefits from collecting such information in terms of yield and stability of annual harvest. Here, we develop a strategic age-structured population model for a long-lived fish with stochastic recruitment, resembling the Norwegian spring-spawning herring (NSSH, Clupea harengus L.). We evaluate how uncertainties in population estimates influence annual yield, spawning stock biomass $(S S B)$, and variation in annual harvest, using both the proportional threshold harvesting $(\mathrm{PTH})$ and the current harvest control rule for NSSH as harvest strategies. Results show that the consequences of a biased estimate are sensitive to the harvest strategy employed. If the harvest strategy is suitably chosen, the benefits of accurate information are low, and less information about the stock is necessary to maintain high average yield. Reduced harvest intensity effectively removes the need for accurate stock estimates. PTH (a variant of the constant escapement strategy) with low harvest ratio and the current NSSH harvest control rule both provide remarkable stability in yield and $S S B$. However,
\end{abstract}

\footnotetext{
*Corresponding author. Ø. Fiksen, e-mail: Oyvind.Fiksen@bio.uib.no

Received by the editors on 4th June 2010. Accepted 15th February 2011. 
decreased uncertainty will often decrease year-to-year variation in harvest and the frequency of fishing moratoria.

KEY WORDS: Age-structured model, management strategy evaluation, multiple uncertainty, Norwegian springspawning herring, optimal harvesting.

1. Introduction. Data about fish stocks are normally obtained through catch and effort records (e.g., from landings statistics and fishermen logbooks), tag and release programs, and research surveys (e.g., Hilborn and Walters [1992]). The data are assimilated into stock assessment models tracking the population's biomass (surplus production models) or cohort dynamics (cohort analyses (VPA) and statistical catch-at-age methods, see, for example, Jennings et al. [2001]). Stock monitoring and assessment is inherently difficult, hampered by a combination of problems such as uncertainties concerning survey methods, data quality, unreported catches, and high costs of obtaining information. Thus, stock abundance estimates are subject to a combination of process, observation, and model uncertainties (Francis and Shotton [1997], Regan et al. [2002], Harwood and Stokes [2003]).

The accuracy of stock estimates depends on the quality and quantity of information about the fish stock (see, e.g., Chen et al. [2003]). Coefficients of variation $(C V)$ in estimates of population sizes are believed to typically be in the range $0.1-0.5$ (Lande et al. [1994]), but they may even be larger than 1 (Engen et al. [1997]). Increased effort in data collection and analyses usually reduces stock uncertainty, but does this necessarily improve the performance of the management system, given that reducing uncertainty is inherently costly? Surprisingly, few studies have addressed how uncertainty of stock estimates affects fishery systems (see Clark and Kirkwood [1986], Frederick and Peterman [1994], Engen et al. [1997], Aanes et al. [2002], Moxnes [2003], Kaitala et al. [2003], Mäntyniemi et al. [2009]). Particularly, a more rigorous theory on how multiple uncertainties influence yields and its variance under alternative control rules are warranted (Bence et al. [2008], Deroba and Bence [2008]).

Our aim here is to explore consequences of uncertainty in stock estimate in some detail. We take Norwegian spring-spawning herring (NSSH, Clupea harengus L.) as our starting point, but our aim is not 


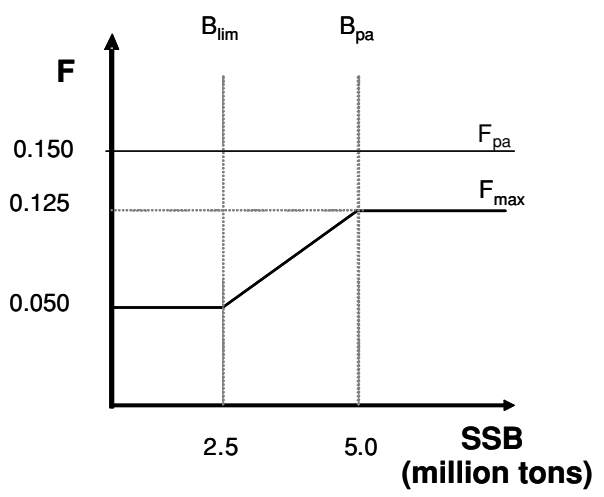

FIGURE 1. Current harvest control rule for Norwegian spring-spawning herring (Clupea harengus L.) ICES [2007]. ICES have advised fishing mortality rate $F$ not to exceed 0.15 per year $\left(F_{p a}\right)$, and in the agreed management plan the maximum fishing mortality has been set to 0.125 per year $\left(F_{\max }\right)$. If the $S S B$ falls below the precautionary biomass of 5.0 million tons $\left(B_{p a}\right)$, the fishing mortality is to be gradually decreased until $F=0.050$ per year, which is the lowest set fishing mortality, to be applied when the $S S B$ is less than the lowest acceptable biomass of 2.5 million tons $\left(B_{\text {lim }}\right)$.

come up with concrete recommendations applicable to NSSH; rather, we use NSSH as an example of a long-lived fish stock that is managed using a harvest strategy that requires stock size estimate as its key input parameter. We use the model to explore how recruitment variability and harvest control rules influence the value of an accurate estimate. In addition to the harvest control rule currently in use for NSSH (Figure 1), we also consider proportional threshold harvesting (PTH) strategies. With PTH only a proportion of the stock above a critical biomass threshold is harvested, which may be appropriate when stock estimates are uncertain (Clark and Kirkwood [1986], Engen et al. [1997], Kaitala et al. [2003], Enberg [2005]). The PTH is a variation of the constant escapement policy (Deroba and Bence [2008]), where the two are identical if the harvest ratio is 1 . PTH was introduced by Engen et al. [1997], and has proven to be a robust strategy for NSSH (Lillegård et al. [2005]).

Our study falls into the category of strategic modeling, specifically management strategy evaluation management strategy evaluation (MSE); see Holland and Herrera [2009], with focus on increasing the 
knowledge about a given phenomenon in general, whereas tactical models usually aim at making predictions for a particular stock or population (see, e.g., Tjelmeland \& Røttingen [2009] for NSSH). If one would be interested in more tactical viewpoint a useful methodology could be to use the possibilities provided by fisheries libraries in $\mathrm{R}$ (FLR; e.g., Hillary [2009]), where also a full-fledged MSE can be carried out (e.g., Smith et al. [1999], Kell et al. [2005]). However, as our intention is only to study the consequences of biased stock size estimate in general, and not in any given fisheries system in particular, we have chosen to use basic population dynamics modeling methods.

\section{The Model.}

2.1. The age-structured stochastic population model. We model the dynamics of NSSH population using a discrete-time agestructured population model that includes a stochastic and densitydependent recruitment function. The purpose is neither to reproduce the dynamics nor the management of NSSH precisely, but rather to explore some general properties of uncertainty in fish stock estimates using NSSH as a prototypic example of a long-lived exploited fish population. This model can thus be considered as our "operating model," and allows us to sample the population as if we were using actual data. Note that we have chosen not to include a stock assessment model, but ignore that step of the management process. The uncertainty of stock estimate can be considered to contain also uncertainty stemming from assessment. The sequence of events in the model is illustrated in Figure 2. The model is programmed in Fortran 90 (Compaq Visual Fortran 90) and is solved within minutes on a desktop computer.

The abundance $N$ of age-class $i+1$ at time $t+1$ is determined by the number alive at age $i$, time $t$, minus the individuals that disappear through fishing and natural mortality:

$$
N_{i+1, t+1}=N_{i, t}\left(1-h_{t}\right) \exp \left(-M_{i}\right)
$$

Here, $M_{i}$ is the instantaneous natural mortality rate at age $i$, and $h_{t}$ is the true proportion harvested (explained below). Natural mortality differs between juvenile and adult age classes, being relatively high until 


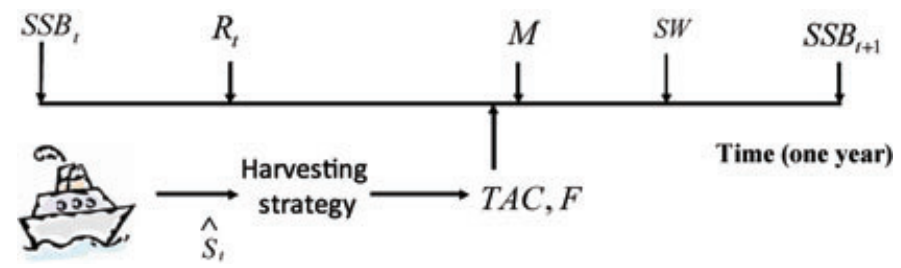

FIGURE 2. The scheduling of events within each year in the model. All updates of the "real" population are above the time-line ( $S S B$, recruitment natural mortality growth and new $S S B)$, while stock estimates $\left(\hat{S}_{t}\right)$ and harvesting strategies are under the line.

age 2 years $(M=0.9$ per year) and low at 0.15 per year for older fish (Table 1). The values employed here are the same as assumed by the ICES [2007] working group assessing the stock, and also commonly used in the literature (e.g., Patterson [1998], Toresen and Østvedt [2000], Bjørndal et al. [2004], Enberg [2005]).

We take age 16 years as the oldest explicitly modeled age group. Letting recruitment occur at age 0 , the model therefore contains 17 age classes. The number of recruits follows a stochastic Beverton-Holt recruitment function (Zheng [1995], Fiksen and Slotte [2002]):

$$
R=N_{0, t}=\left(\frac{a \cdot S S B_{t}}{b+S S B_{t}}\right) \exp \left(w_{t}\right)
$$

where parameters $a$ and $b$ are $1.88 \times 10^{11}$ and $5.139 \times 10^{6}$ tons, respectively (Fiksen and Slotte [2002]). The term $\exp \left(w_{t}\right)$ represents log-normally distributed environmental stochasticity with mean one and $C V$ equal to $C V_{R}$, which is achieved when the stochastic parameter $w_{t}$ follows a normal distribution $N(\mu, \sigma)$ with $\mu=-\frac{1}{2} \ln \left(1+C V_{R}^{2}\right)$ and $\sigma=\sqrt{\ln \left(C V_{R}^{2}+1\right)}$.

The spawning stock biomass, $S S B$, is a function of body mass $\left(S W_{i}\right)$ and number $\left(N_{i, t}\right)$ of mature individuals in each age class $i$ :

$$
S S B_{t}=\sum_{i=0}^{i=16} S W_{i} \cdot N_{i, t} \cdot M O_{i},
$$

where $M O_{i}$ is the proportion of mature individuals (Table 1). 
TABLE 1. Values employed for maturity ogive $\left(M O_{i}\right.$, proportion of mature individuals in each age class), mean weight at age $\left(S W_{i}\right.$, in $\left.\mathrm{kg}\right)$, and natural mortality rate $\left(M_{i}\right.$, in per year) and selectivity $\left(s_{i}\right)$. Weight and fecundity at age are fixed values averaged over the past 10 years from the ICES Working Group Report. As in the assessment, age 16 is the oldest explicitly modeled age group also representing older individuals.

\begin{tabular}{lllll} 
Age class $(i)$ & $M O_{i}{ }^{\mathrm{a}}$ & $S W_{i}^{\mathrm{a}}$ & $M_{i}^{\mathrm{a}, \mathrm{b}, \mathrm{c}}$ & $s_{i}{ }^{\mathrm{c}}$ \\
\hline 0 & 0 & 0.001 & 0.90 & 0 \\
1 & 0 & 0.014 & 0.90 & 0 \\
2 & 0 & 0.035 & 0.90 & 0 \\
3 & 0.01 & 0.095 & 0.15 & 1 \\
4 & 0.036 & 0.159 & 0.15 & 1 \\
5 & 0.9 & 0.216 & 0.15 & 1 \\
6 & 1 & 0.253 & 0.15 & 1 \\
7 & 1 & 0.285 & 0.15 & 1 \\
8 & 1 & 0.304 & 0.15 & 1 \\
9 & 1 & 0.333 & 0.15 & 1 \\
10 & 1 & 0.346 & 0.15 & 1 \\
11 & 1 & 0.372 & 0.15 & 1 \\
12 & 1 & 0.375 & 0.15 & 1 \\
13 & 1 & 0.380 & 0.15 & 1 \\
14 & 1 & 0.405 & 0.15 & 1 \\
15 & 1 & 0.416 & 0.15 & 1 \\
16 & 1 & 0.421 & 0.15 & 1 \\
\hline
\end{tabular}

${ }^{\mathrm{a}} \mathrm{ICES}[2007]$.

${ }^{\mathrm{b}}$ Patterson [1998].

${ }^{\mathrm{c}}$ Enberg [2005].

The estimate $\hat{S}_{t}$ of the $S S B$ enters the harvest strategy to determine the total allowable catch (TAC) or fishing mortality. We define it as

$$
\widehat{S}_{t}=\max \left[0, S S B_{t} \cdot N\left(1, C V_{\varepsilon}\right)\right]
$$

where $N\left(1, C V_{\varepsilon}\right)$ is a normal deviate with mean equal to one and standard deviation equal to the $C V$ of estimated biomass, $C V_{\varepsilon}$, which 
we term the uncertainty of the estimate of the true $S S B_{t}$. Note that equation (4) prevents negative values, but allows an estimate to be 0 . We let estimated $\hat{S}_{t}$ and true $S S B_{t}$ have identical age structure, such that $\hat{S}_{t}$ also defines estimated number of individuals in each age-class $\left(\hat{N}_{i, t}\right)$. We can then calculate relative estimation error $E_{t}$ as the ratio of $\hat{S}_{t}$ to $S S B_{t}$ each year:

$$
E_{t}=\hat{S}_{t} / S S B_{t},
$$

to determine annual yield from both PTH and the harvest control rule currently in use for NSSH (see below).

2.2. Proportional threshold harvesting. The PTH strategy is determined by two parameters, critical biomass threshold $c$, below which no harvesting occurs, and the harvest ratio above the critical biomass threshold, $H R$. The biomass is expressed in term of harvestable biomass, $H B_{t}$, which, assuming knife-edge selectivity $s_{i}$ at age 3 years (Table 1), includes all biomass above age 3 :

$$
H B_{t}=\sum_{i=0}^{i=16} N_{i, t} \cdot s_{i} \cdot S W_{i} .
$$

The annual yield $Y_{t}$ is then

$$
Y_{t}=\left\{\begin{array}{cl}
0 & \text { if } \hat{S}_{t}<c \\
{\left[\left(H B_{t} \cdot E_{t}\right)-c\right] \cdot H R} & \text { if } \hat{S}_{t} \geq c
\end{array}\right.
$$

constrained to the interval $0 \leq Y_{t} \leq H B_{t}$. Here, $E_{t}$ is the relative estimation error, that is, the ratio between the estimated and the true $S S B$ (equation (5)), and the realized harvest will therefore depend both on the estimate bias and the true stock size.

The true harvest proportion $h_{t}$ (equation (1)) is the fraction of the total harvestable biomass removed by fishing:

$$
h_{t}=Y_{t} / H B_{t} .
$$

Including the selectivity parameter, the population dynamics (equation (1)) is 


$$
N_{i+1, t+1}=N_{i, t}\left(1-s_{i} \cdot h_{t}\right) \exp \left(-M_{i}\right)
$$

2.3. Present NSSH harvest control rule. With the current harvest strategy (Figure 1), the TAC or yield in biomass can be found from fishing mortality $F_{t}$ as

$$
Y_{t}=\sum_{i=0}^{i=16}\left(N_{i, t} \cdot E_{t} \cdot S W_{i}\right)\left[1-\exp \left(-F_{t} \cdot s_{i}\right)\right] .
$$

Note that TAC will also depend both on the estimate bias $\left(E_{t}\right)$ and the true stock size $\left(N_{i, t}\right)$. This yield is transformed to the harvest ratio through (8) for updating of age classes in (9).

3. Simulations. All simulations were first run for 1000 years without harvesting to let the population be independent of initial conditions. Our aim was not to solve practical management questions thus we chose to run the model for 50,000 years, with stock uncertainty $C V_{\varepsilon}$ ranging from 0 to 1 . Within this long-time frame the average results of the simulations could be compared even under large variability in recruitment and stock estimate. For each $C V_{\varepsilon}$, we recorded (i) average annual yield; (ii) average $S S B$; (iii) the $C V$ in annual harvest; and (iv) the proportion of years with fishing moratoria.

For PTH, we explored the effect of stock size uncertainty under three different threshold levels ( $c$ in equation (7)). The first value was 2.5 million tons, which is the lowest acceptable biomass for NSSH (ICES [2007]). Then we employed an intermediate threshold at 4.2 million tons, previously suggested as optimal for NSSH (Lillegård et al. [2005]), and an arbitrary, high threshold of 5.5 million tons. For each of these thresholds, we varied $H R$ from 0 to 1 . Simulating a harvest ratio of 1 implies a constant escapement strategy where all biomass above the threshold is removed (see, e.g., Lande et al. [1994], Lande [1995], Whittle and Horwood [1995], Lande et al. [2003], Enberg [2005]).

\section{Results.}

4.1. Proportional threshold harvesting. Our simulations with low recruitment variance $\left(C V_{R}=0.1\right)$ and three different threshold 
regimes revealed that the harvest ratio determines how yield is influenced by uncertainty in the stock abundance estimate (Figure 3). For harvest ratios exceeding $\sim 0.2$, the yield declined with increasing uncertainty of the estimate. Maximum yield was found for low harvest ratios $(0.2-0.3)$, and in this region yield was insensitive to uncertainty in the estimate for any of the thresholds. On the other hand, when the stock abundance estimate was accurate, yield was relatively insensitive to the actual harvest ratio employed.

Both variability in yield (Figure 4A) and the frequency of fishing moratoria (Figure 4B) increased with uncertainty of the population estimate. Similar results were found for all three threshold regimes explored - and also under high recruitment variance $\left(C V_{R}=2.0\right.$, not shown). Naturally, variation in annual harvest was significantly higher under high recruitment variability $\left(C V_{Y} \sim 1.0-4.5\right)$.

The average $S S B$ was quite similar under low $\left(C V_{R}=0.1\right)$ and high $\left(C V_{R}=2.0\right)$ recruitment variance (Figure $5 \mathrm{~A}$ and $\left.\mathrm{B}\right)$. The regime with the highest threshold maintained the highest $S S B$. With higher uncertainty about the stock size, average $S S B$ decreased under both low and high variance in recruitment (Figure $5 \mathrm{~A}$ and $\mathrm{B}$ ). With high uncertainty of the estimate and high harvest ratios, the average $S S B$ was well below the critical thresholds in the respective harvest regimes, explaining the high variation in yield at these combinations of uncertainty and harvest ratio. Annual fluctuations of $S S B$ increased with uncertainty of the estimate, particularly when the population had low recruitmentdriven natural fluctuations (Figure $5 \mathrm{C}$ ). For high $C V_{R}$, fishing had a dampening effect on stock variability in the lower end of stock size uncertainty (Figure 5D).

The age when fish became susceptible to the fishery had considerable influence on how stock size uncertainty affected annual yield (Figure 6). If fish are exposed to harvesting at age 5 years (Figure $6 \mathrm{C}$ ) instead of age 1 (Figure $6 \mathrm{~A}$ ), a lower fraction of the population is vulnerable to fishing, and the consequences of a biased estimate are strongly reduced (seen as a flatter yield surface), while yield is doubled over a range of uncertainties and harvest ratios.

Yield was quite insensitive to accuracy of the population estimate for all harvest thresholds for a harvest ratio of 0.2 (Figure 7A). At higher harvest ratios (e.g., 0.6 in Figure 7B), it is more critical to hit the right threshold than to have accurate stock information. 

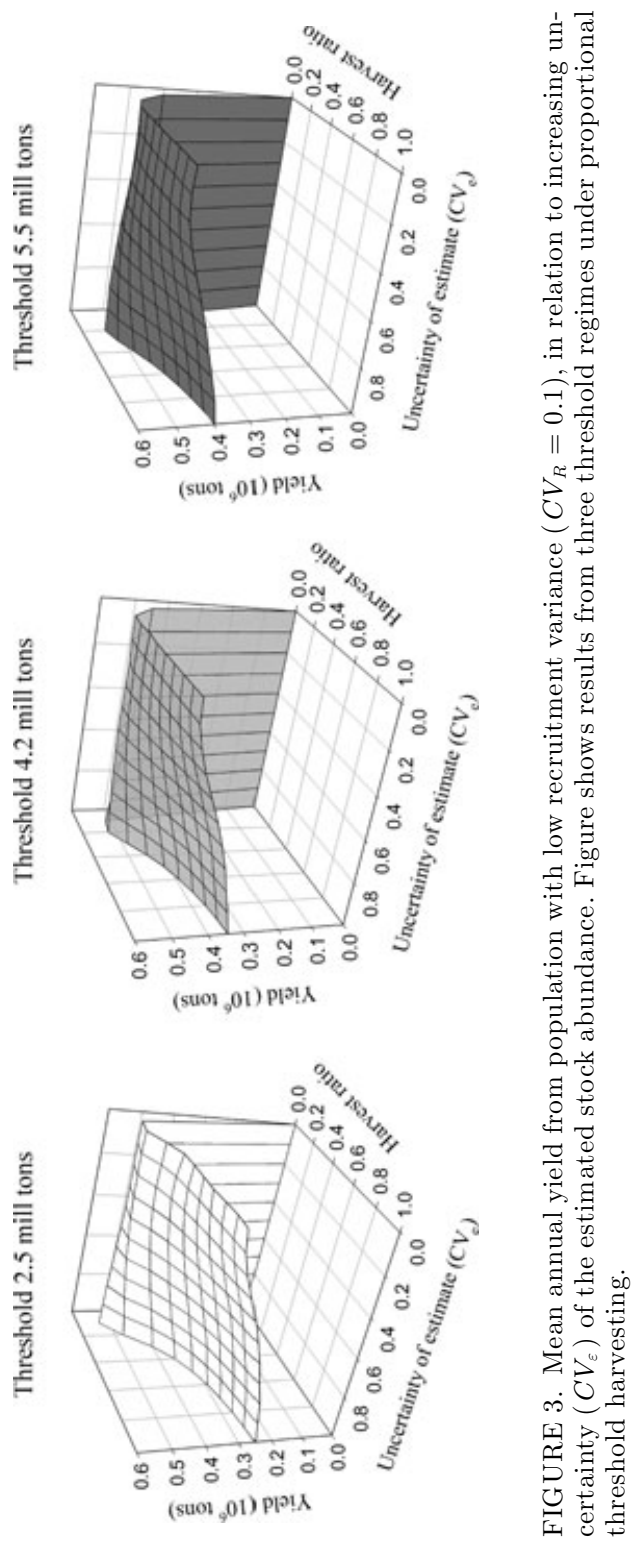

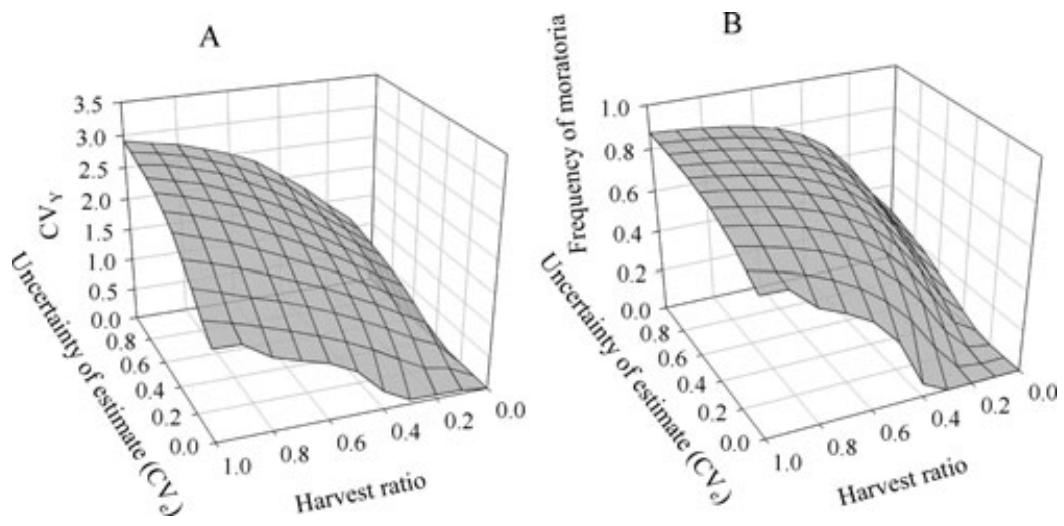

FIGURE 4. (A) Variation in annual yield $\left(C V_{Y}\right)$ and (B) frequency of fishing moratoria over 50,000 years with increasing uncertainty of the stock abundance estimate under low recruitment variance $\left(C V_{R}=0.1\right)$. Results are from proportional threshold harvesting employing a threshold regime of 4.2 million tons. Similar results were obtained when testing both lower and higher threshold regimes used in Figure 3.

4.2. The current NSSH harvest control rule. With the twostep harvest control rule currently applied to NSSH (Figure 1), the average annual yield was almost invariant to both uncertainty of the estimate and variance in recruitment (Figure 8A). Variance in annual harvest (Figure 8B) and frequency of fishing moratoria (not shown) were more sensitive to uncertainty and recruitment variability. However, even under high uncertainty the frequency of moratoria never exceeded $\sim 0.3$, despite the uncertainty of the population estimate being $150 \%\left(C V_{\varepsilon}=1.5\right)$. Yield was higher and variance lower for the applied rule compared to any PTH strategy (Figure $8, c=4.2$ million tons and $H R=0.6)$, although these harvest control rules are quite similar if $H R$ is kept near the optimum of $\sim 0.2$ (see Figures 2 and 6 ). None of the harvest strategies were particularly sensitive to recruitment variance.

$S S B$ under the NSSH harvest control rule decreased slightly with uncertainty of the population estimate (Figure 9A), but average $S S B$ was above $B_{p a}$ and fishing mortality remained therefore around maximum $F=F_{\max }=0.125$ per year (harvest ratio $\sim 0.12$ ). This low harvest rate facilitates a stable population, stable yield, and low frequency of 

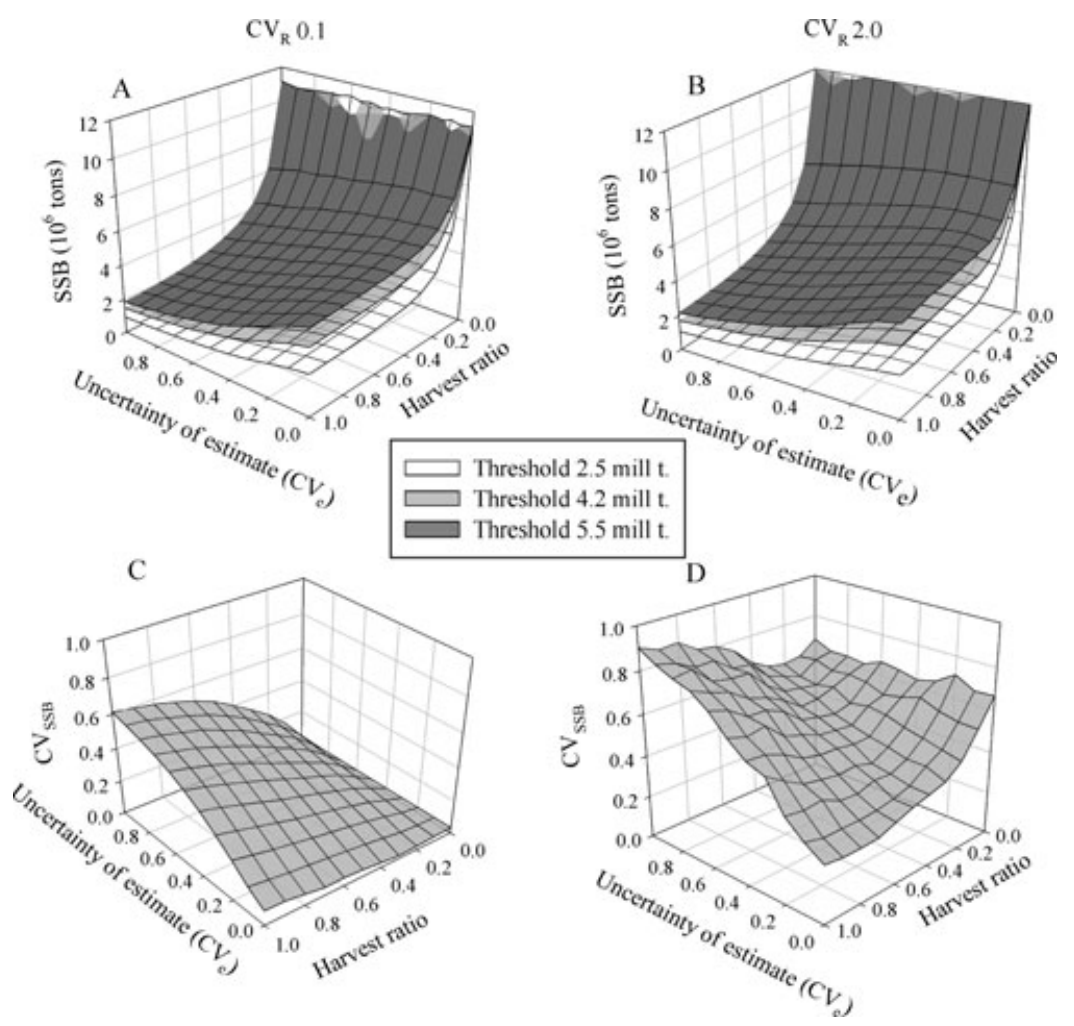

FIGURE 5. Average $S S B$ (A and B) and variation $C V_{S S B}(\mathrm{C}$ and $\mathrm{D})$ under low (0.1; left panels) and high (2.0; right panels) variation in recruitment with proportional threshold harvesting and three different thresholds $(c)$. For variation ( $\mathrm{C}$ and $\mathrm{D})$, only the intermediate threshold $c=4.2$ million tons are shown.

fishing moratoria even with limited information about the population. Fluctuations in $S S B$ were weakly influenced by variation in recruitment and uncertainty of the population estimate (Figure 9B), never exceeding $C V$ of 0.2 in our simulations.

5. Discussion. Our main objective for developing the model was to better understand the generalities of interactions between 


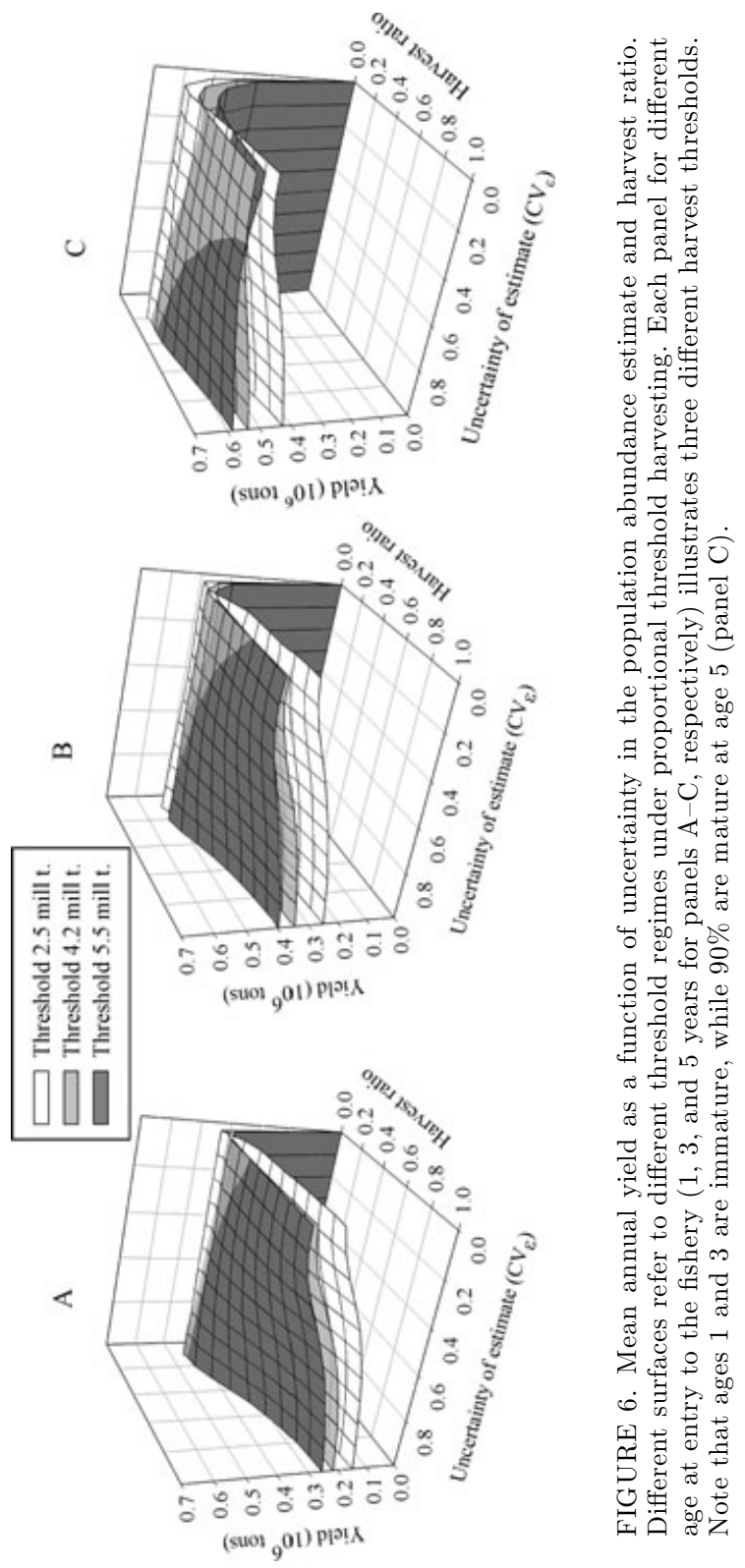



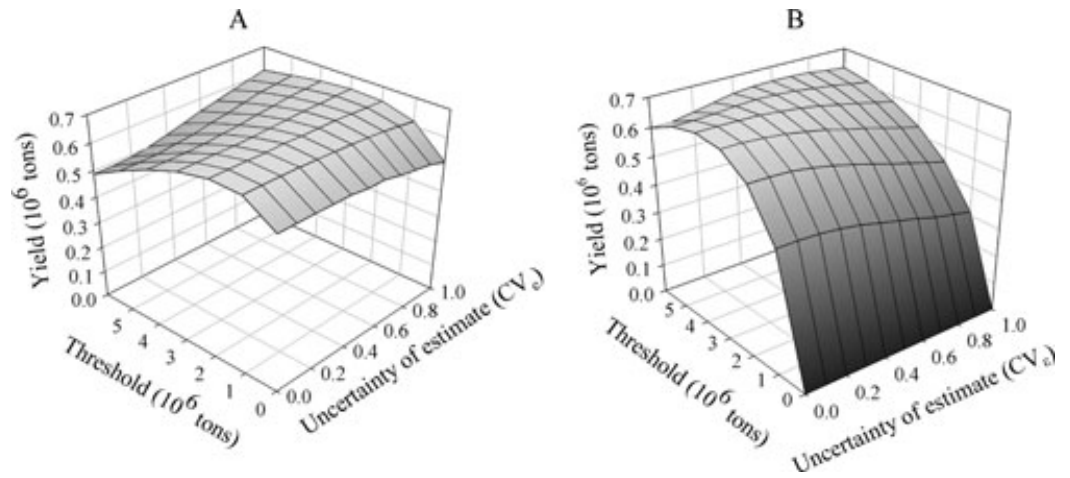

FIGURE 7. Mean annual yield as a function of uncertainty in population abundance estimate and threshold in the proportional harvesting strategy. (A) Harvest ratio $=0.2$ and $(\mathrm{B})$ harvest ratio $=0.6$.
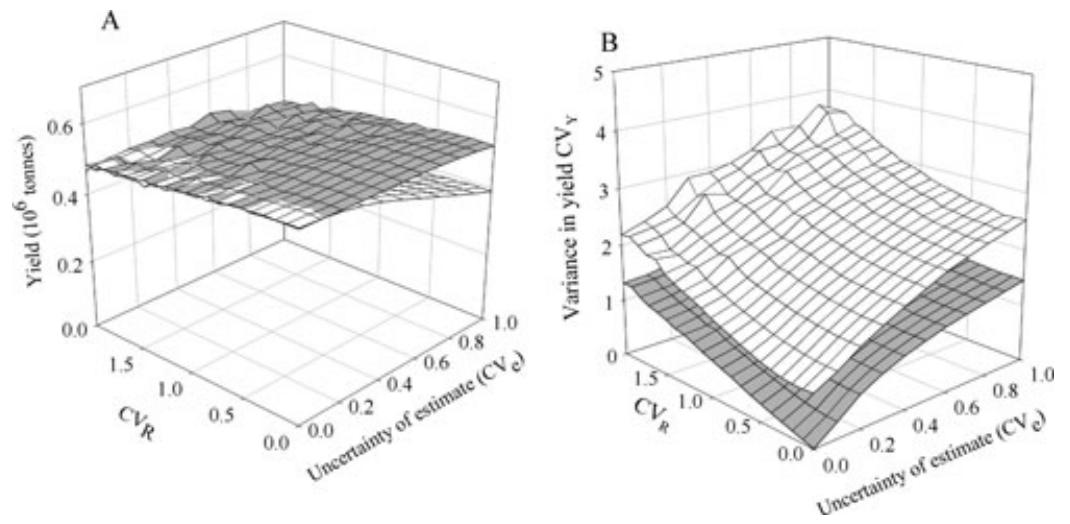

FIGURE 8. (A) Yield and (B) variance in yield under the two-step NSSH harvest control rule (gray surfaces) and for proportional threshold harvesting with threshold 4.2 million tons and harvest ratio 0.6 (white surface).

harvesting strategy, inherent stock variability, and uncertainty in abundance estimates. As pointed out by Deroba and Bence [2008], more research is needed on the interactions between control rules, assessment errors, and natural variability in population dynamics. The theory in 

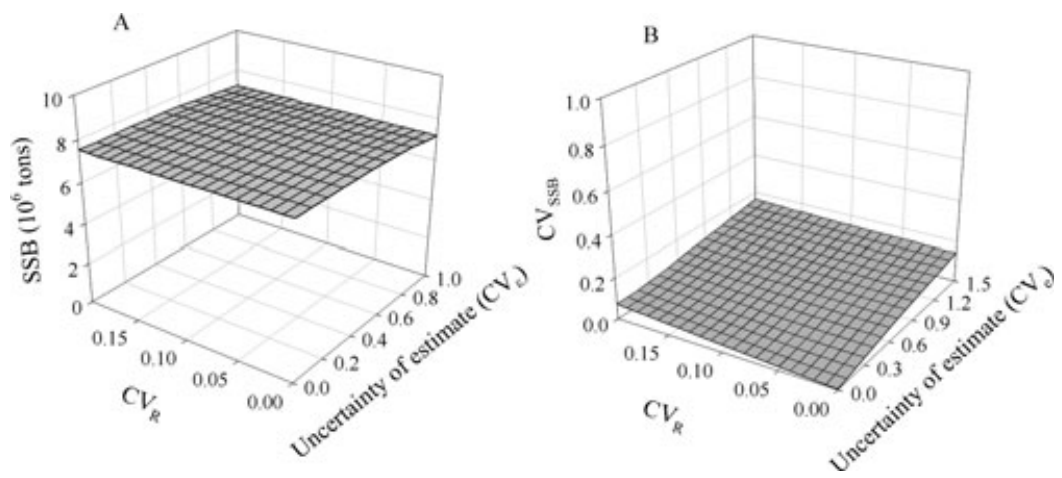

FIGURE 9. The NSSH harvest control rule. (A) Average and (B) variation $(C V)$ in $S S B$ for recruitment variance $\left(C V_{R}\right)$ and uncertainty of the population estimate $\left(C V_{\varepsilon}\right)$.

this area is confusing, and this may have hampered the implication of theory to fisheries management (Holland and Herrera [2009]).

One key lesson from our model is that the consequences of a biased estimate are strongly dependent on the harvest strategy imposed on the population. When fishing rates are kept low, there is no apparent effect of information uncertainty on the average long-term yield or $S S B$. This is perhaps not surprising, but it adds support to management practices that are conservative: by keeping harvest rates low, relatively high yields can be maintained, and the need for accurate stock assessment is reduced. In more intensively harvested stocks, the dependence on accurate stock assessment for high and stable yield is much higher. One option to increase profitability of harvesting when costs involved in stock assessment are high is therefore to simultaneously reduce fishing intensity and assessment effort.

Both harvest strategies we examined confirmed that the degree of uncertainty in the population estimate will affect variation in annual yield and frequency of fishing moratoria (Engen et al. [1997], Aanes et al. [2002]; see also Haltuch et al. [2008, 2009] for sensitivity of different management reference points to biases in stock estimates). For stakeholders, stability of harvest may be just as important as the total potential yield for deciding if a harvest strategy is appropriate (Hilborn 
and Walters [1992], Walters and Martell [2004]). The benefits of accurate stock information in terms of variation in annual yield decreased when the inherent recruitment variability of the population was high (Figure 8b).

The NSSH harvest control rule generated a remarkable resilience in the model and performed best of the strategies tested here in terms of maximizing yield while minimizing variation in yield, frequency of fishing moratoria, and variability in $S S B$. This can be explained by the low target fishing pressure imposed under this harvest strategy, which never exceeds $F_{\max }=0.125$ per year (i.e., fishing never removes more than $12 \%$ of the estimated biomass). The long-term average $S S B$ emerging from PTH with harvest ratio $>0.1$ will be in the range $2-6$ million tons (Figure 5A and B), and the current NSSH will therefore mainly be in the region where harvesting $(F$, but also $H R$ ) will fluctuate with stock size. The current rule and PTH therefore have very similar effects on population and yield. Our study and a previous study by Enberg [2005] suggest that two-stage harvest regimes may be even more advantageous than PTH, which has previously been suggested as optimal for maximizing yield and minimizing variation in annual harvest (Engen et al. [1997], Lande et al. [2003], Lillegård et al. [2005]). Anyway, if the $C V$ in assessment estimates are in the range $0.1-0.5$ (Engen et al. [1997]), then both yield and variance of yield will be close to optimum in all the PTH strategies in Figures 5 and 6 .

Our model may miss important aspects of a real-world fishery system, such as Allee effects that hinder recoveries from low stock sizes, biases in stock estimates depending on stock size, inherent delays in assessing the stock and regulating the fishery, multispecies management considerations, and the political difficulties in implementing harsh management actions such as closing a fishery. However, simple models are often useful tools to develop our intuition about harvested populations (Touzeau et al. [2000], Enberg [2005]), and the model is quite realistic on the biological parts. We have not included economic variables such as economic yield or profit, costs of harvesting at various stock levels etc. (see Steinshamn [1998], Sethi et al. [2005], Johannesen and Skonhoft [2009], Tahvonen [2009]). Nor do we explicitly include costs of the stock assessment, which would be particularly interesting, at least in small-scale fisheries. Our model is an example of management strategy evaluation recently reviewed by Holland and Herrera [2009]. 
MSE could be appealing to managers faced with large uncertainties in the biological basis of the stock dynamics because it identifies robust strategies. In our case, we found the existing management rule to be very robust to measurement uncertainty.

Process, observation, and model uncertainties are irreducible (Regan et al. [2002], Harwood and Stokes [2003]). Cochrane [1999] argues that attempts to measure all uncertainties of any system will never succeed, and uncertainties will rather be underestimated. Reducing the uncertainty of population estimates may increase yield and most likely reduce the variation in annual harvest. However, a suitable harvest control rule considerably reduces the importance of an accurate estimate. In our study we do not separate between the different error (or uncertainty) components, but treat our noise term as including all the abovementioned components, and simply call the error term "uncertainty of the estimate." Results of a recent study Punt et al. [2008] are in line with our conclusions, as they found that implementation error, corresponding to estimating the population numbers incorrectly (which is very close to our "uncertainty of the estimate"), is an important determinant of the interannual variation in catches.

Adjusting gear selectivity may also reduce the importance of detailed stock information. For costly assessments, there is a limit to how much information can cost effectively be collected. Stock estimates with an uncertainty of $C V \sim 1$ are relatively cheap to obtain (Walters and Pearse [1996]). The simplest and most cost effective option might often be to reduce overall harvesting pressure while at the same time ensuring that fish are not exposed to fishing too early.

Acknowledgments. We thank Per Sandberg, Elizabeth Brooks, and anonymous reviewers for comments on an earlier version of this manuscript, and the Bergen Research Foundation and the Norwegian Research Council (projects 173417 and 802030) for funding.

\section{REFERENCES}

S. Aanes, S. Engen, B.E. Saether, T. Willebrand, and V. Marcstrom [2002], Sustainable Harvesting Strategies of Willow Ptarmigan in a Fluctuating Environment, Ecol. Appl. 12, 281-290.

J.R. Bence, M.W. Dorn, B.J. Irwin, and A.E. Punt [2008], Recent Advances in the Evaluation and Implementation of Harvest Policies, Fish. Res. 94, 207-209. 
T. Bjørndal, D.V. Gordon, V. Kaitala, and M. Lindroos [2004], International Management Strategies for a Straddling Fish Stock: A Bio-Economic Simulation Model of the Norwegian Spring-Spawning Herring Fishery, Environ. Res. Econ. 29, 435-457.

Y. Chen, L. Chen, and K.I. Stergiou [2003], Impacts of Data Quantity on Fisheries Stock Assessment, Aquat. Sci. 65, 92-98.

C.W. Clark and G.P. Kirkwood [1986], On Uncertain Renewable Resource Stocks: Optimal Harvest Policies and the Value of Stock Surveys, J. Environ. Econ. Manag. 13, 235-244.

K.L. Cochrane [1999], Complexity in Fisheries and Limitations in the Increasing Complexity of Fisheries Management, ICES J. Mar. Sci. 56, 917-926.

J.J. Deroba and J.R. Bence [2008], A Review of Harvest Policies: Understanding Relative Performance of Control Rules, Fish. Res. 94, 210-223.

K. Enberg [2005], Benefits of Threshold Strategies and Age-Selective Harvesting in a Fluctuating Fish Stock of Norwegian Spring Spawning Herring Clupea harengus, Mar. Ecol. Prog. Ser. 298, 277-286.

S. Engen, R. Lande, and B.-E. Sæther [1997], Harvesting Strategies for Fluctuating Populations Based on Uncertain Population Estimates, J. Theor. Biol. 186, 201-212.

$\varnothing$. Fiksen and A. Slotte [2002], Stock-Environment Recruitment Models for Norwegian Spring Spawning Herring (Clupea harengus), Can. J. Fish. Aquat. Sci. 59, 211-217.

R.I.C.C. Francis and R. Shotton [1997], "Risk" in Fisheries Management: A Review, Can. J. Fish. Aquat. Sci. 54, 1699-1715.

S.W. Frederick and R.M. Peterman [1994], Choosing Fisheries Harvest Policies: When Does Uncertainty Matter?, Can. J. Fish. Aquat. Sci. 52, 291-306.

M.A. Haltuch, A.E. Punt, and M.W. Dorn [2008], Evaluating Alternative Estimators of Fishery Management Reference Points, Fish. Res. 94, 290-303.

M.A. Haltuch, A.E. Punt, and M.W. Dorn [2009], Evaluating the Estimation of Fishery Management Reference Points in a Variable Environment, Fish. Res. 100, $42-56$.

J. Harwood and K. Stokes [2003], Coping with Uncertainty in Ecological Advice: Lessons from Fisheries, Trends Ecol. Evol. 18, 617-622.

R. Hilborn and C.J. Walters [1992], Quantitative Fisheries Stock AssessmentChoice, Dynamics \& Uncertainty, Chapman and Hall, London.

R. Hillary [2009], An Introduction to FLR Fisheries Simulation Tools, Aquat. Liv. Res. 22, 225-232.

D. S. Holland and G. E. Herrera [2009], Uncertainty in the Management of Fisheries: Contradictory Implications and a New Approach, Mar. Resour. Econ. 24, 289-299.

ICES [2007], Report of the Working Group on Northern Pelagic and Blue Whiting Fisheries (WGNPBW), CM 2007/ACFM:29.

S. Jennings, M.J. Kaiser, and J.D. Reynolds [2001], Marine Fisheries Ecology, Blackwell Science Ltd., Oxford. 
A.B. Johannesen and A. Skonhoft [2009], Growth and Measurement Uncertainty in an Unregulated Fishery, Nat. Res. Model. 22, 370-392.

V. Kaitala, N. Jonzén, and K. Enberg [2003], Harvesting Strategies in a Fish Stock Dominated by Low-Frequency Variability: The Norwegian Spring-Spawning Herring (Clupea harengus), Mar. Res. Econ. 18, 263-274.

L.T. Kell, G.M. Pilling, G.P. Kirkwood, M. Pastoors, B. Mesnil, K. Korsbrekke, P. Abaunza, R. Aps, A. Biseau, P. Kunzlik, C. Needle, B.A. Roel, and C. UlrichRescan [2005], An Evaluation of the Implicit Management Procedure Used for Some ICES Roundfish Stocks, ICES J. Mar. Sci. 62, 750-759.

R. Lande [1995], Optimal Harvesting of Fluctuating Populations with a Risk of Extinction, Am. Nat. 145, 728-745.

R. Lande, S. Engen, and B.E. Sæther [1994], Optimal Harvesting, Economic Discounting and Extinction Risk in Fluctuating Populations, Nature 372, 88-90.

R. Lande, S. Engen, and B.E. Sæther [2003], Stochastic Population Dynamics in Ecology and Conservation, Oxford University Press, London.

M. Lillegård, S. Engen, B.E. Sæther, and R. Toresen [2005], Harvesting Strategies for Norwegian Spring-Spawning Herring, Oikos 110, 567-577.

S. Mäntyniemi, S. Kuikka, M. Rahikainen, L.T. Kell, and V. Kaitala [2009], The Value of Information in Fisheries Management: North Sea Herring as an Example, ICES J. Mar. Sci. 66, 2278-2283.

E. Moxnes [2003], Uncertain Measurements of Renewable Resources: Approximations, Harvesting Policies and Value of Accuracy, J. Environ. Econ. Manag. 45, 85-108.

K.R. Patterson [1998], Biological Modelling of the Norwegian Spring-Spawning Herring Stock, Rep. No. 1/98, Fisheries Research Services, Aberdeen.

A.E. Punt, M.W. Dorn, and M.A. Haltuch [2008], Evaluation of Threshold Management Strategies for Groundfish Off the US West Coast, Fish. Res. 94, 251-266.

H.M. Regan, M. Colyvan, and M.A. Burgman [2002], A Taxonomy and Treatment of Uncertainty for Ecology and Conservation Biology, Ecol. Appl. 12, 618-628.

G. Sethi, C. Costello, A. Fisher, M. Hanemann, and L. Karp [2005], Fishery Management under Multiple Uncertainty, J. Environ. Econ. Manag. 50, 300-318.

A.D.M. Smith, K.J. Sainsbury, and R.A. Stevens [1999], Implementing Effective Fisheries-Management Systems-Management Strategy Evaluation and the Australian Partnership Approach, ICES J. Mar. Sci. 56, 967-979.

S.I. Steinshamn [1998], Implications of Harvesting Strategies on Population and Profitability in Fisheries, Mar. Resour. Econ. 13, 23-36.

O. Tahvonen [2009], Optimal Harvesting of Age-Structured Fish Populations, Mar. Resour. Econ. 24, 147-169.

S. Tjelmeland and I. Røttingen [2009], Objectives and Harvest Control Rules in the Management of the Fishery of Norwegian Spring-Spawning Herring, ICES J. Mar. Sci. 66, 1793-1799.

R. Toresen and O.J. Østvedt [2000], Variation in Abundance of Norwegian Spring-Spawning Herring (Clupea harengus, Clupeidae) throughout the 20th Century and the Influence of Climatic Fluctuations, Fish Fish. 1, 231-256. 
S. Touzeau, M. Lindroos, V. Kaitala, and J. Ylikarjula [2000], Economic and Biological Risk Analysis of the Norwegian Spring-Spawning Herring Fishery, Ann. Oper. Res. 94, 197-217.

C.J. Walters and S.J. Martell [2004], Fisheries Ecology and Management, Princeton University Press, Princeton.

C. Walters and P.H. Pearse [1996], Stock Information Requirements for Quota Management Systems in Commercial Fisheries, Rev. Fish Biol. Fish. 6, 21-42.

P. Whittle and J. Horwood [1995], Population Extinction and Optimal Resource Management, Philos. Trans. R. Soc. B 350, 179-188.

J. Zheng [1995], Herring Stock-Recruitment Relationships and Recruitment Patterns in the North Atlantic and Northeast Pacific Oceans, Fish. Res. 26, 257-277. 